\title{
Effect of sugar fatty acid esters on rumen fermentation in vitro
}

\author{
BY M. WAKITA AND S. HOSHINO* \\ Faculty of Agriculture, Mie University, Tsu 514, Japan
}

(Received 25 September 1986 - Accepted 17 June 1987)

1. The effect of sugar fatty acid esters (SFEs; currently used as food additives for human consumption) on rumen volatile fatty acids (VFA) and gas production was studied with sheep rumen contents in vitro.

2. Some SFEs having monoester contents of more than $70 \%$ increased the molar proportion of propionate in conjunction with reduction in the acetate : propionate ratio when the individual SFE was added to rumen contents in a final concentration of $4 \mathrm{~g} / \mathrm{l}$. Laurate sugar ester was the most potent propionate enhancer and rumen gas depressor, the effective dose being as low as $1 \mathrm{~g} / \mathrm{l}$ in a final concentration. Fatty acid esters other than SFEs had little, if any, effect on rumen VFA production and their molar proportions.

3. Approximately $50 \%$ of laurate sugar ester was hydrolysed by in vitro incubation with rumen fluid for $2 \mathrm{~h}$. The addition of fatty acids and sucrose was also effective in the alterations of rumen VFA and gas production. However, the effect of SFEs on in vitro rumen fermentation was significantly greater than that of their constituent fatty acids or sucrose, or both. Accordingly, the effect appeared to be ascribed to the complex action of SFE itself and to its constituents, free fatty acids and sucrose.

4. SFEs, at the level of $4 \mathrm{~g} / 1$, reduced substantially the froth formation (ingesta volume increase) and seemed to be effective for the prevention of bloat.

Sugar fatty acid esters (SFEs), synthesized from sucrose and long-chain fatty acids, usually derived from tallow, are mixtures composed of different amounts of monoesters and polyesters (Table 1). Most of these non-ionic surfactants contain mono-, di- and triesters in varying proportions and have a wide hydrophile-lipophile balance ranging from 1 to 15 . Hence, SFEs are currently used as additives for various foods such as ice cream, several cream products and sweets because of their excellent emulsifying capability.

Extensive studies have been conducted to improve the efficiency of rumen fermentation by controlling the number of microbes and their activities with chemical agents (Chalupa, 1977). Of these chemical agents ionophore antibiotics (Bergen \& Bates, 1984) and methane inhibitors (Czerkawski \& Breckenridge, 1975; Stanier \& Davies, 1981; Davies et al. 1982; Chalupa et al. 1983) can be used to increase energy and protein utilization in ruminants. Effects of fatty acids (Blaxter \& Czerkawski, 1966; Demeyer \& Henderickx, 1967; Chalupa et al. 1983; Jenkins \& Palmquist, 1984), oils (Blaxter \& Czerkawski, 1966; McAllan et al. 1983; Sutton et al. 1983) or their calcium soaps (Jenkins \& Palmquist, 1984) on rumen fermentation are also of interest. Little is known about the effect of SFEs on rumen fermentation.

The present study was undertaken to examine the effect of SFEs on rumen volatile fatty acids (VFA) and gas production in vitro. A preliminary report of the present study has appeared (Wakita et al. 1985).

\section{MATERIALS AND METHODS \\ SFEs and other fatty acid esters}

The compositions of the esters are shown in Table 1. Most of the SFEs (nos. 1-8) consisted of stearate and palmitate esters with different degrees of esterification, and the rest (nos. 9 and 10) contained principally behenate, laurate or oleate instead of stearate and palmitate esters. Other types of fatty acid esters (nos. 12-15) were used for comparison with SFEs.

$$
\text { * For reprints. }
$$




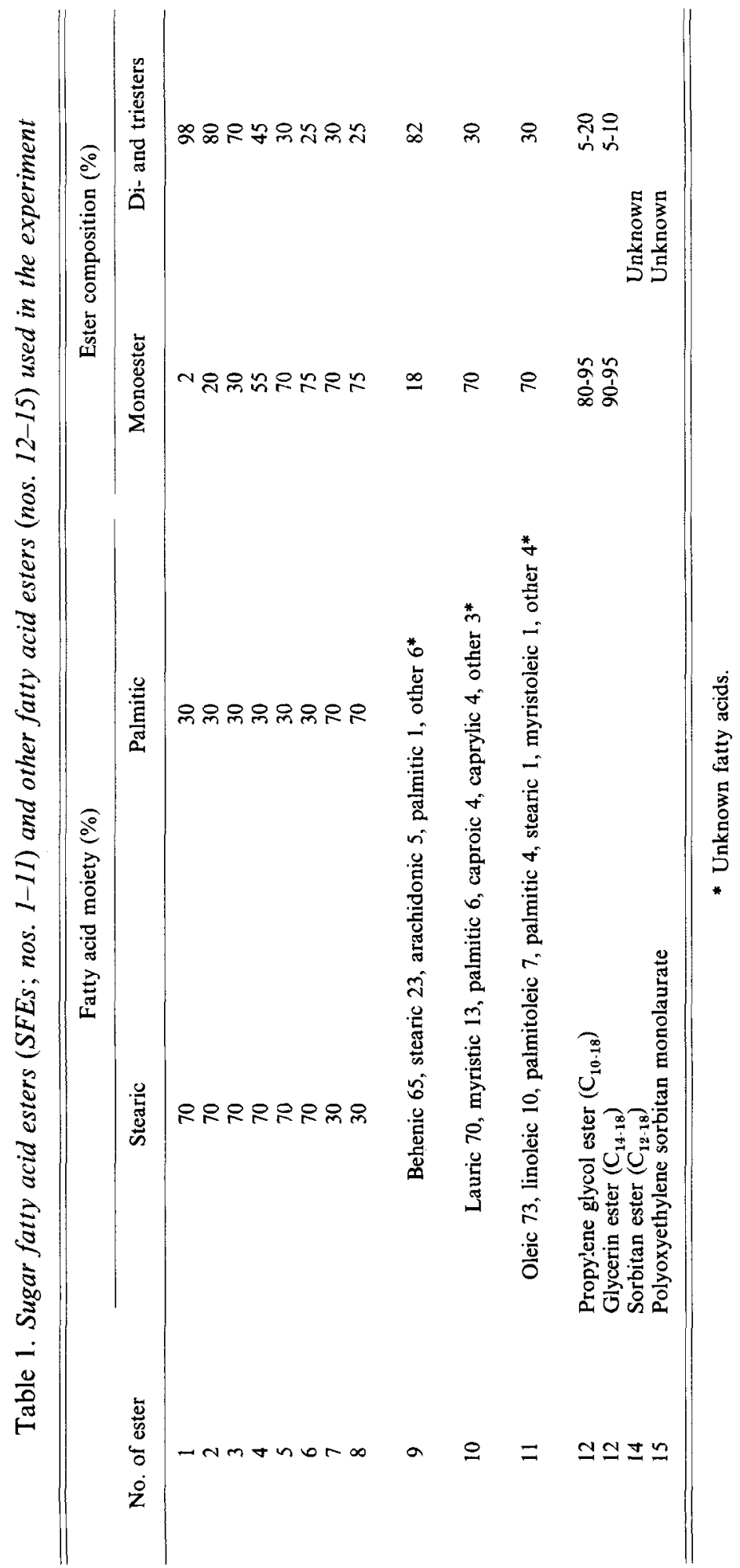


All the ester compounds were obtained from Mitsubishi Kasei Industry Co. (Yokkaichi, Japan).

\section{Rumen fluid, incubation, and analysis of products}

Samples of rumen contents were taken before the morning feed from sheep (fitted with rumen fistulas) which were given feed in two equal meals (at 09.00 and 19.00 hours) of $350 \mathrm{~g}$ lucerne (Medicago sativa) hay-cubes and $200 \mathrm{~g}$ concentrate feed. Rumen samples were strained through two layers of surgical gauze and used within $\mathbf{3 0}$ min of sampling.

To determine the effect of esters on VFA production by rumen contents in vitro, the strained rumen fluid $(10 \mathrm{ml})$ was pipetted into a $25 \mathrm{ml}$ test-tube containing $0.22 \mathrm{~g}$ finelyground feed (a mixture of 7 parts lucerne hay-cubes and 4 parts concentrate). Each ester compound listed in Table 1 was dissolved or suspended in distilled water to give a concentration of $44 \mathrm{mg} / \mathrm{ml}$ and in most experiments $1 \mathrm{ml}$ of this solution was added to the test-tube so that the final concentration of ester was $44 \mathrm{mg} / 11 \mathrm{ml}$. After replacing the air in the test-tube with mixed gas (nitrogen-carbon dioxide; $95 \cdot 5, \mathrm{v} / \mathrm{v}$ ) the tube was closed with a rubber stopper and incubated in a water-bath at $39^{\circ}$ for $2 \mathrm{~h}$ with occasional mixing to prevent the layering of feed particles. Except for the omission of ester compounds, the control tube was prepared and incubated in the same manner. After $2 \mathrm{~h}$ incubation the reaction mixture was mixed with $1 \mathrm{ml} 2 \cdot 0 \mathrm{M}$-sulphuric acid, followed by centrifugation. A portion $(5 \mathrm{ml})$ of the supernatant fraction was mixed with $1 \mathrm{ml} 2.5 \mathrm{M}$-sulphuric acid containing $m$-phosphoric acid $(200 \mathrm{~g} / 1)$, allowed to stand overnight, and then centrifuged. The resulting supernatant fraction was used for VFA determination by gas-liquid chromatography as described by Suto (1973). The VFA production during $2 \mathrm{~h}$ incubation was calculated by subtracting VFA concentration in the blank tube, in which the reaction was stopped just before incubation, from that in the experimental tube.

In the determination of gas production $10 \mathrm{ml}$ of the strained rumen fluid was incubated for $1 \mathrm{~h}$ at $39^{\circ}$ in reaction vessels consisting of glass tubes $(15 \mathrm{~mm}$ in diameter and $80 \mathrm{~mm}$ in length) fitted with rubber balloons at one end. The tube was charged with the same feed $(0.22 \mathrm{~g})$ and an ester $(4 \mathrm{~g} / 1)$ as for the VFA incubations. After expelling the air in the reaction vessel by squeezing the balloon and thus pushing the reaction mixture up, the top was closed tightly with a rubber stopper and the whole immersed in a water-bath at $39^{\circ}$. After $1 \mathrm{~h}$ incubation, $1 \mathrm{ml} 2.0 \mathrm{M}$-sulphuric acid was injected through the stopper and the resulting gas phase was separated from the reaction mixture by injecting $1 \mathrm{ml}$ liquid paraffin. Samples of gas $(0.5 \mathrm{ml})$ at $39^{\circ}$ were taken out with a $2.5 \mathrm{ml}$ gas-syringe and the composition was analysed by a gas-liquid chromatographic procedure (Ushida et al. 1982). The remaining gas in the vessel was withdrawn into an air-tight $10 \mathrm{ml}$ syringe to measure total gas volume at $39^{\circ} . \mathrm{CO}_{2}$ and methane volumes were calculated by multiplying a total gas volume by the component percentage of individual gas. The gas production during $1 \mathrm{~h}$ incubation was calculated by a method similar to the calculation of VFA production.

The ability of rumen contents to froth was assessed by measurement of the ingesta volume increase (IVI) carried out as described by Jacobson et al. (1957), except that in the present experiment $50 \mathrm{ml}$ rumen fluid were used, instead of $200 \mathrm{ml}$ in the original method with cattle. The rumen fluid $(50 \mathrm{ml}$ in a $100 \mathrm{ml}$ graduated cylinder) was allowed to stand at $39^{\circ}$ in a water-bath for $45 \mathrm{~min}$ and the increase in volume was recorded and presented as percentage increase.

Degradation of ester. The concentration of SFE no. 10 was estimated by the colorimetric method of Hodge \& Hofreiter (1962) which gave a linear calibration curve between optical density and sucrose contents in SFE molecules. Assuming that sucrose liberated from SFE is fermented rapidly by rumen microbes, the method could give an approximate amount of undegraded SFE. The procedure was as follows. The strained rumen fluid was incubated with feed and with or without SFE as for VFA incubations. Every $30 \mathrm{~min} 1 \mathrm{ml} 1.0 \mathrm{M}$ - 
sulphuric acid was added to a tube followed by centrifugation; the supernatant fraction was kept. A portion of the supernatant fraction $(1 \mathrm{ml})$ was mixed with $1 \mathrm{ml}$ phenol solution $(50 \mathrm{~g} / 1)$ and $5 \mathrm{ml} 18 \mathrm{M}$-sulphuric acid, mixed well and allowed to stand at room temperature for $30 \mathrm{~min}$. The optical density of the developed yellow colour was determined at $490 \mathrm{~nm}$ with a spectrophotometer. The degradability of the ester was calculated by making corrections for blank values.

The results were analysed statistically by Dunnett's $t$ statistic (Dunnett, 1955).

\section{RESULTS}

\section{Effects of SFEs on rumen VFA production in vitro}

Tables 2 and 3 show total VFA production and their composition in rumen fluid incubated with SFE (4 g/1) or without SFE (control) in vitro. Of six SFEs containing $70 \%$ stearate and $30 \%$ palmitate moieties (Table 1, nos. 1-6), some SFEs (nos. 5 and 6) increased total VFA concentration and propionate proportion in conjunction with a decrease in acetate proportion, but the rest of these SFEs (nos. 1-4) had little effect on propionate proportion (Table 2). SFEs containing $70 \%$ palmitate and 30\% stearate moieties (nos. 7 and 8 ) altered total VFA production and their molar proportion in the same pattern as the above SFEs (nos. 5 and 6 ) did, the differences in VFA molar proportion and acetate : propionate (A:P) ratio from control values being significant (Table 2).

SFEs having $70 \%$ monoester of different fatty acid moieties (nos. 10 and 11) also increased the molar proportion of propionate and decreased the A:P ratio (Table 3), while the SFE having $18 \%$ monoester (no. 9) had no effect on propionate proportion. This effect of SFEs appeared to be closely associated with the monoester content in the products, since SFEs containing more than $70 \%$ monoester increased VFA, in particular propionate proportion, but those containing less than $55 \%$ monoester had little effect on VFA molar proportion (Tables 2 and 3). Among the effective SFEs having the same ester composition ( $70 \%$ monoester and $30 \%$ di- and triester, nos. 5, 7, 10 and 11), laurate ester (no. 10) was the most potent propionate enhancer, followed by nos 7, 5 and 11 (Tables 2 and 3). Of two SFE pairs with the same ester composition (nos. 6 and 8, and nos. 5 and 7), palmitate ester tended to be more effective than stearate ester (Table 2).

Because of the large effect of laurate ester (no. 10), the effect of increasing doses of the ester on total VFA and propionate production was examined but not reported here in detail. The additions of the ester ranging from 0.1 to $0.8 \%$ in a final concentration significantly increased propionate molar proportion with a concurrent decrease of acetate proportion in a dose-response manner, but the additions had little effect on total VFA production.

The addition of fatty acid esters at $4 \mathrm{~g} / 1$ other than SFEs (nos. 12-15) caused no significant effect on total VFA production and their relative proportions, except for valerate.

\section{Degradation rate of SFEs and effects of the structural fatty acids or sucrose, or both, on $V F A$ production in vitro}

The apparent degradability of SFE no. 10 is shown in Table 4. The ester was degraded gradually during incubation and $56 \%$ of the added ester seemed to be degraded after $2 \mathrm{~h}$. If the SFE or products inhibit the degradation of endogenous sugar, then the true degradation of SFE is greater than the apparent degradation as given in Table 4.

An attempt was made to determine whether the effect of SFEs is due to their structural fatty acids or sucrose, or both (see Table 5). The amounts of sucrose and fatty acids added to the reaction mixture was similar to those in the corresponding SFE $(4 \mathrm{~g} / 1)$ as described 
Sugar fatty acid esters and rumen activity

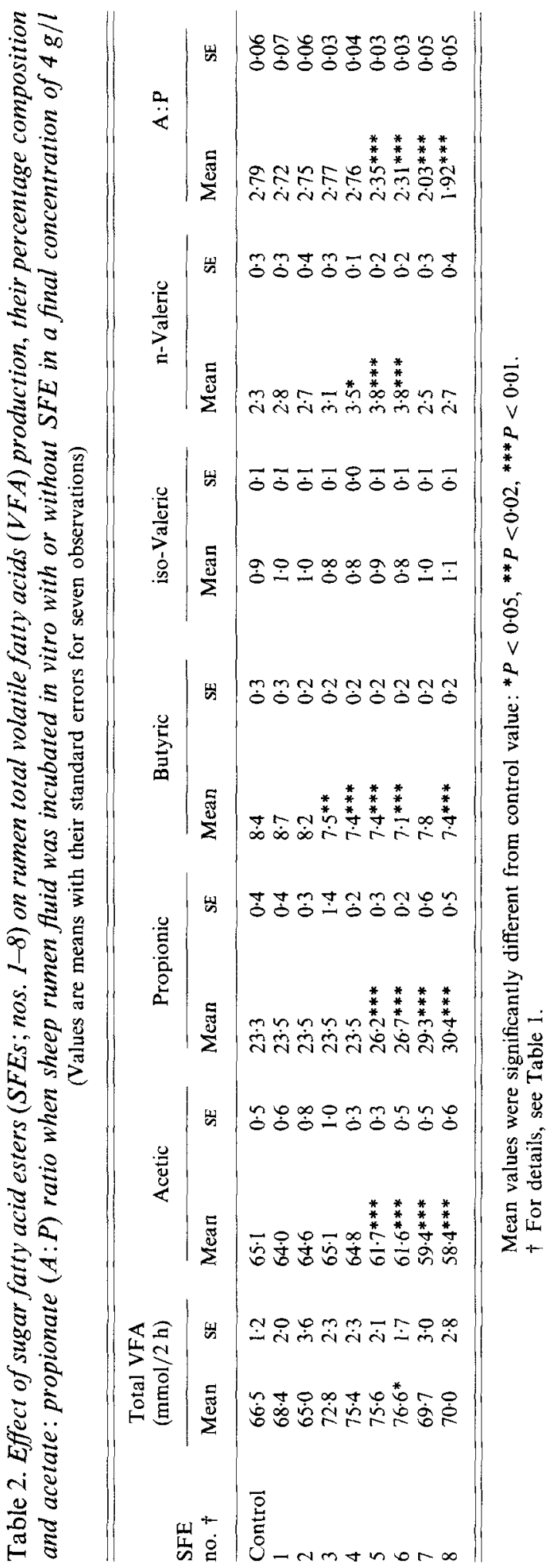




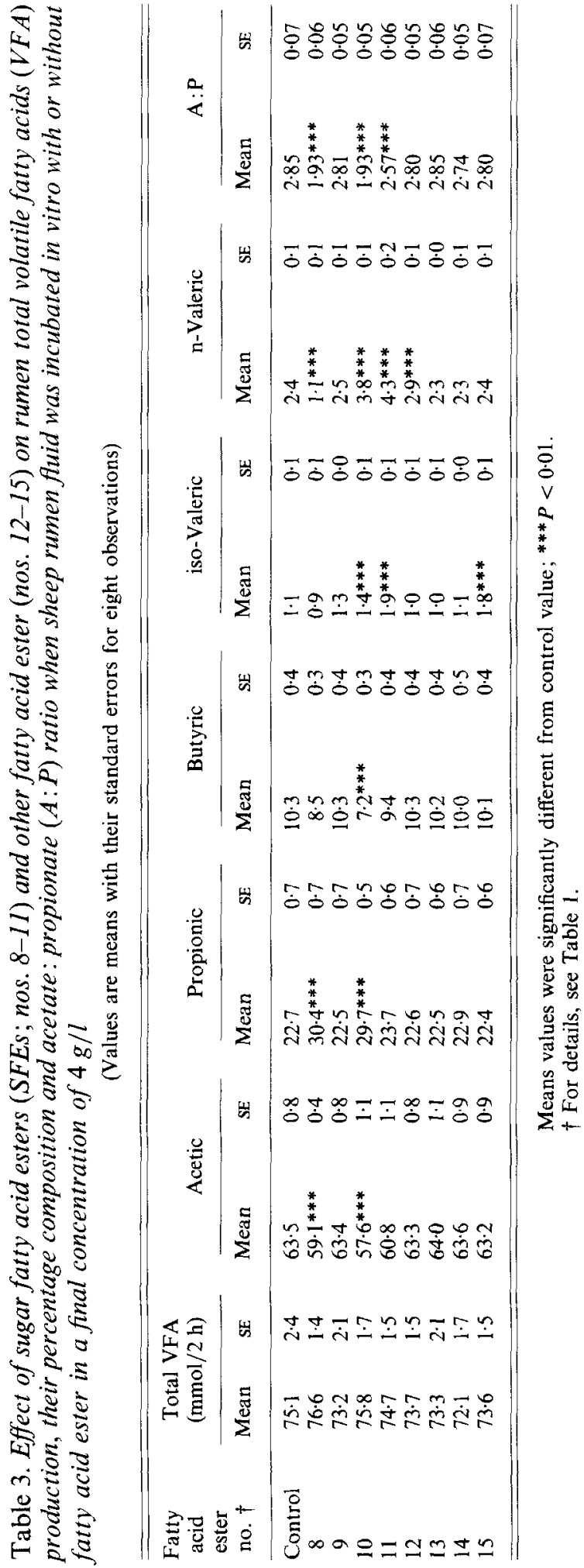


Table 4. Degradability of sugar fatty acid ester (SFE; no. 10*)

(Values are means with their standard errors for three observations)

\begin{tabular}{|c|c|c|c|c|c|c|}
\hline \multirow{3}{*}{$\begin{array}{l}\text { Incubation } \\
\text { period } \\
\text { (min) }\end{array}$} & \multicolumn{4}{|c|}{$\begin{array}{l}\text { Phenol-sulphuric acid } \\
\text { active substances (mg/ml) }\end{array}$} & \multirow{3}{*}{$\begin{array}{l}\text { Difference } \\
\text { (D) }\end{array}$} & \multirow{3}{*}{$\begin{array}{c}\text { Degradability } \\
\text { of SFE } \\
\text { (4.05-D)/4.05 }\end{array}$} \\
\hline & \multicolumn{2}{|c|}{$\mathrm{SFE}(4 \mathrm{mg} / \mathrm{ml})$} & \multicolumn{2}{|c|}{ Blank } & & \\
\hline & Mean & $\mathbf{S E}$ & Mean & $\mathrm{SE}$ & & \\
\hline 0 & $13 \cdot 16$ & 0.13 & $9 \cdot 11$ & 0.22 & 4.05 & 0 \\
\hline 30 & $7 \cdot 20$ & 0.09 & $4 \cdot 17$ & 0.30 & 3.03 & 0.25 \\
\hline 60 & 6.66 & 0.18 & $4 \cdot 14$ & 0.08 & $2 \cdot 53$ & 0.38 \\
\hline 90 & $6 \cdot 15$ & 0.10 & 4.03 & 0.05 & $2 \cdot 12$ & $0-48$ \\
\hline 120 & 5.70 & 0.08 & 3.93 & 0.06 & 1.77 & 0.56 \\
\hline
\end{tabular}

* For details, see Table 1.

in Table 5. All additives slightly increased total VFA production in comparison with the control. Some additives (except fatty acids) increased propionate and decreased acetate and $A: P$ ratio, a maximum effect being observed with SFE additives (Table 5). The result suggests that sucrose may serve as a precursor for VFA production and that fatty acids have some effect on VFA production, but the effect of SFEs is not due completely to their hydrolysates per se, because there were significant differences between the effects of the SFEs and their constituents (Table 5).

\section{Effects of SFEs on rumen gas production and IVI}

Effects of two SFEs (nos. 7 and 10) and their constituents on gas production are shown in Table 6. Both SFEs depressed gas production, particularly methane production, with no accumulation of hydrogen (Table 6). The inhibitory effect of SFE no. 7 on rumen gas production was more potent than that of its structural fatty acids or fatty acids plus sucrose, but the effect of SFE no. 10 was less potent than that of its fatty acids or combinations of fatty acids and sucrose (Table 6).

The effect of SFEs on IVI is shown in Table 7. The addition of SFE (nos. 7 and 10) inhibited froth formation in rumen contents during incubation in comparison with the control.

\section{DISCUSSION}

Our results demonstrate that some SFEs stimulated rumen VFA production, in particular propionate production, and inhibit gas production which could lead to the reduction of the IVI value of rumen contents. Based on the potency of SFEs inducing these changes, it seems likely that monoester contents over $70 \%$ are required for these changes to take place (Tables 2 and 3), and that the SFE effects are associated with the intact SFE molecule as a surfactant and its constituents, fatty acids and sucrose. The latter view appears to be supported by the differential effects between SFEs and their constituents (Tables 5 and 6) and the degradation rate of SFE (Table 4).

It is well documented that free fatty acids, particularly higher unsaturated fatty acids, alter rumen fermentation towards more propionate and less methane (Blaxter \& Czerkawski, 1966; Demeyer \& Henderickx, 1967; Chalupa et al. 1984). Several mechanisms by which the acids inhibit methanogenesis have been suggested, e.g. a direct toxic effect towards methanogenic bacteria (Prins et al. 1972) and a physico-chemical inhibition, involving adhesion of the acids to the cell, possibly uncoupling energy systems (Galbraith 


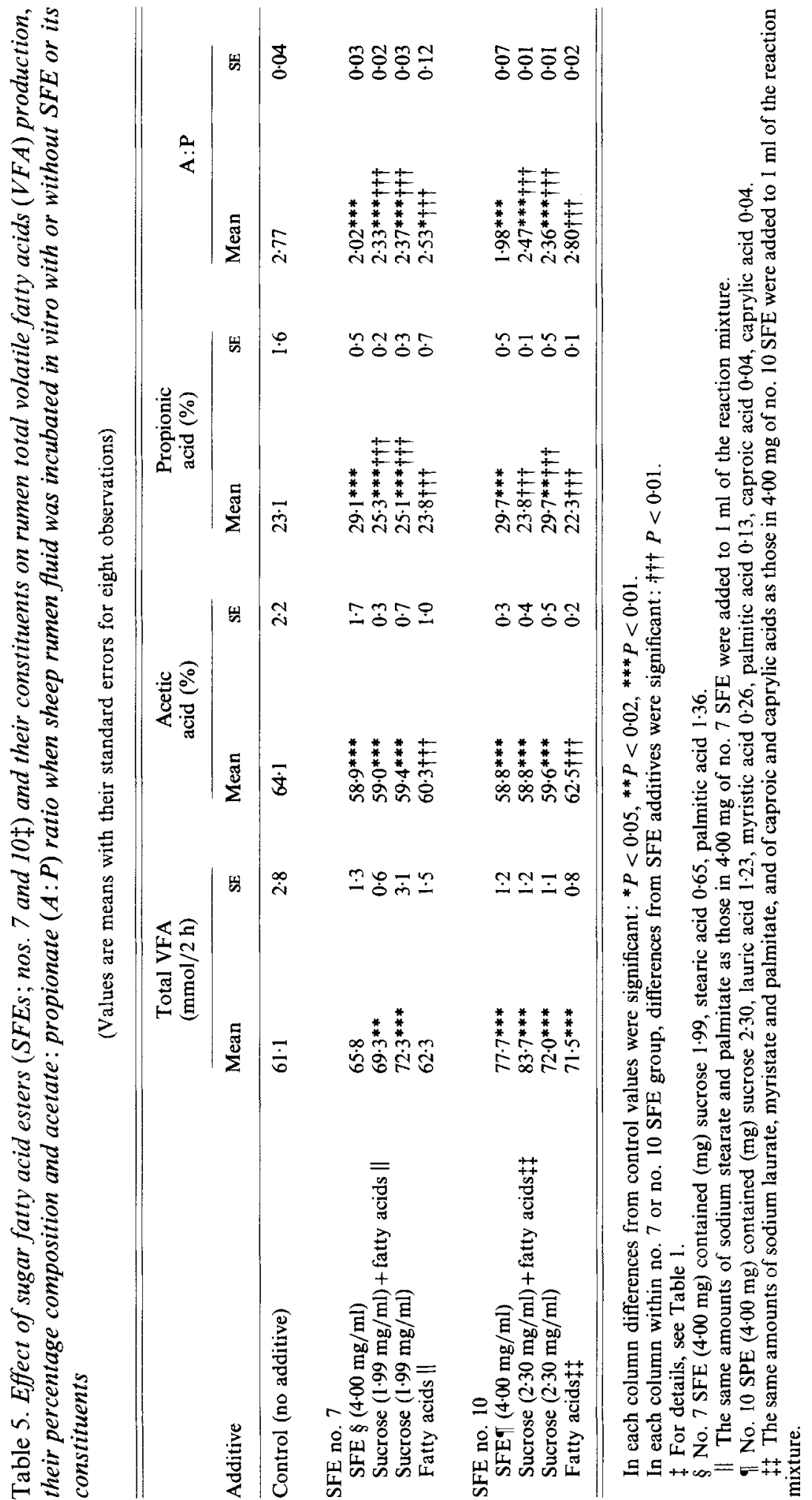


Table 6. Effect of sugar fatty acid esters (SFEs; nos. 7 and 10\$) and their constituents on rumen gas production ( $\mathrm{ml} / \mathrm{h}$ per $10 \mathrm{ml}$ rumen fluid) when sheep rumen fluid was incubated with or without SFE or its constituents

(Values are means with their standard errors for three observations)

\begin{tabular}{|c|c|c|c|c|c|c|c|}
\hline \multirow[b]{2}{*}{ Additive } & \multicolumn{2}{|c|}{ Total gas } & \multicolumn{2}{|c|}{$\mathrm{CO}_{2}$} & \multicolumn{2}{|c|}{$\mathrm{CH}_{4}$} & \multirow[b]{2}{*}{$\mathrm{H}_{2}$} \\
\hline & Mean & $\mathrm{SE}$ & Mean & SE & Mean & $\mathbf{S E}$ & \\
\hline Control (no additive) & $3 \cdot 5$ & $0 \cdot 1$ & $2 \cdot 9$ & $0 \cdot 1$ & 0.6 & $0 \cdot 0$ & $\operatorname{Tr}$ \\
\hline \multicolumn{8}{|l|}{ SFE no. 7} \\
\hline SFE $\S(4.00 \mathrm{mg} / \mathrm{ml})$ & $2 \cdot 6$ & 0.6 & $2 \cdot 3$ & 0.5 & $0 \cdot 3^{* * *}$ & $0 \cdot 0$ & $\operatorname{Tr}$ \\
\hline Sucrose $(1.99 \mathrm{mg} / \mathrm{ml})+$ fatty acids $\|$ & $3 \cdot 4$ & 0.2 & $2 \cdot 8$ & 02 & $0.6+t+t$ & $0 \cdot 0$ & Tr \\
\hline Fatty acids \| & $3 \cdot 3$ & $0-3$ & $2 \cdot 7$ & 0.4 & $0-6+\dagger+$ & $0 \cdot 0$ & $\operatorname{Tr}$ \\
\hline \multicolumn{8}{|l|}{ SFE no. 10} \\
\hline $\mathrm{SFE}(4.00 \mathrm{mg} / \mathrm{ml})$ & $2 \cdot 3^{*}$ & 0.1 & $2 \cdot 0$ & $0 \cdot 0$ & $0 \cdot 3^{* * *}$ & $0 \cdot 0$ & $\operatorname{Tr}$ \\
\hline Sucrose $(2 \cdot 30 \mathrm{mg} / \mathrm{ml})+$ fatty acids $\ddagger$ & $1 \cdot 7^{* * *}$ & $0 \cdot 1$ & $1 \cdot 5^{* *}$ & $0 \cdot 1$ & $0 \cdot 2^{* * *+1+\dagger}$ & $0 \cdot 0$ & $\operatorname{Tr}$ \\
\hline Fatty acids $¥ \ddagger$ & $1 \cdot 4 * * *$ & 0.2 & $1 \cdot 1 * * *$ & 0.1 & $0 \cdot 3^{* * *}$ & $0 \cdot 0$ & $\operatorname{Tr}$ \\
\hline
\end{tabular}

Tr, trace.

In each column differences from control values were significant: ${ }^{*} P<0.05,{ }^{* *} P<0.02,{ }^{* * *} P<0.01$.

In each column within no. 7 or no. $10 \mathrm{SFE}$ group, differences from SFE additives were significant : $\dagger \dagger+P<0.01$.

$\ddagger$ For details, see Table 1 .

$\S$ No. 7 SFE $(4.00 \mathrm{mg})$ contained $(\mathrm{mg})$ sucrose 1.99 , stearic acid $0 \cdot 65$, palmitic acid $1 \cdot 36$.

II The same amounts of sodium stearate and palmitate as those in $4.00 \mathrm{mg}$ of no. 7 SFE were added to $1 \mathrm{ml}$ of the reaction mixture.

To. 10 SFE $(4.00 \mathrm{mg})$ contained $(\mathrm{mg})$ sucrose $2 \cdot 30$, lauric acid $1 \cdot 23$, myristic acid $0 \cdot 26$, palmitic acid $0 \cdot 13$, caproic acid 0.04, caprylic acid 0.04.

t屯 The same amounts of sodium laurate, myristate and palmitate, and of caproic and caprylic acids as those in $4.00 \mathrm{mg}$ of no. $10 \mathrm{SFE}$ were added to $1 \mathrm{ml}$ of the reaction mixture.

Table 7. Effect of sugar fatty acid esters (SFEs; nos. 7, 10 and 11) on rumen ingesta volume increase $(I V I ; \%)$ when sheep rumen fluid was incubated in vitro with or without SFE in a final concentration of $4 \mathrm{~g} / \mathrm{l}$

(Values are means with their standard errors for three observations)

\begin{tabular}{|c|c|c|c|c|c|c|}
\hline \multirow{3}{*}{$\begin{array}{l}\text { SFE } \\
\text { no. } \dagger\end{array}$} & \multicolumn{6}{|c|}{ IVI during: } \\
\hline & \multicolumn{2}{|c|}{$15 \mathrm{~min}$} & \multicolumn{2}{|c|}{$30 \mathrm{~min}$} & \multicolumn{2}{|c|}{$45 \mathrm{~min}$} \\
\hline & Mean & $\mathrm{SE}$ & Mean & SE & Mean & $\mathrm{SE}$ \\
\hline Control & $10 \cdot 6$ & 0.7 & $19 \cdot 7$ & $0 \cdot 9$ & $27 \cdot 3$ & $1 \cdot 3$ \\
\hline 7 & $4 \cdot 7^{* * *}$ & $0-3$ & $7 \cdot 9^{* * *}$ & 0.6 & $11 \cdot 3^{* * *}$ & 0.7 \\
\hline 10 & $4 \cdot 7^{* * *}$ & 0.7 & $7 \cdot 0^{* * *}$ & $0 \cdot 6$ & $11 \cdot 3^{* * *}$ & 0.7 \\
\hline 11 & $4 \cdot 2^{* * *}$ & $0 \cdot 1$ & $6 \cdot 7^{* * *}$ & $0 \cdot 3$ & $9 \cdot 3 * * *$ & 0.3 \\
\hline
\end{tabular}

In each column differences from control values were significant: ${ }^{* * *} P<0 \cdot 01$.

† For details, see Table 1 .

\& Miller, 1973). Because of active esterases in rumen fluid (Table 4; Czerkawski \& Breckenridge, 1975), fatty acids and sucrose released from SFEs can partly contribute to the alteration of rumen fermentation towards more propionate and less methane.

With higher fatty acids and oils, the increase in molar proportion of propionate is associated with depression of fibre digestion (Blaxter \& Czerkawski, 1966; McAllan et al. 
1983; Sutton et al. 1983; Jenkins \& Palmquist, 1984). Long-chain fatty acids inhibit the growth of certain rumen bacteria (Henderson, 1973), the growth of cellulolytic species being markedly inhibited by the addition of oleic acid to the culture medium (Maczulak et al. 1981). In contrast, tallow calcium soaps do not lower digestibilities of fibre in the rumen (Jenkins \& Palmquist, 1984). Assuming that 40\% SFEs remain intact in the rumen for $2 \mathrm{~h}$ (Table 4), it is possible that SFEs as well as tallow soaps may have a far less inhibitory effect on fibre digestion in the rumen than free fatty acids alone.

It has been shown that the addition of non-ionic surfactants (sucrose monostearate and sucrose monopalmitate) to fungal cultures results in marked increases in yields of amylase (Takahashi et al. 1960), cellulase, sucrase, xylanase and glucanase (Reese \& Maguire, 1969), the action appearing to be an effect of the surfactant on cell permeability. The undegraded SFEs could act as a surfactant on rumen microbes in the same way, and stimulate microbial uptake of nutrients by emulsifying fermentation medium and by a possible alteration of permeability of cell membranes, which in turn could enhance VFA production. However, the detailed mechanisms of SFE action, including selection for rumen microbes, are uncertain and must await elucidation.

In view of the marked IVI reducing activity of SFEs, they could be useful in the treatment of bloat in ruminants. In fact, several surfactants have been widely used for the prevention or treatment of both legume and grain bloats (Clarke \& Reid, 1974; Laby, 1975).

The authors gratefully acknowledge Mitsubishi Chemical Industries Limited for their generous gift of sugar fatty acid esters and financial support.

\section{REFERENCES}

Bergen, D. G. \& Bates, D. D. (1984). Journal of Animal Science 58, $1465-1483$.

Blaxter, K. L. \& Czerkawski, J. (1966). Journal of the Science of Food and Agriculture 17, 417-421.

Chalupa, W. (1977). Journal of Animal Science 46, 585-599.

Chalupa, W., Patterson, J. A., Parish, R. C. \& Chow, A. W. (1983). Journal of Animal Science 57, $186-194$.

Chalupa, W., Rickabaugh, B., Kronfeld, D. S. \& Sklan, D. (1984). Journal of Dairy Science 67, 1439-1444.

Clarke, R. T. J. \& Reid, C. S. W. (1974). Journal of Dairy Science 57, 753-785.

Czerkawski, J. W. \& Breckenridge, G. (1975). British Journal of Nutrition 34, 429-446.

Davies, A., Nwaonu, H. N., Stanier, G. \& Boyle F. T. (1982). British Journal of Nutrition 47, 565-576.

Demeyer, D. 1. \& Henderickx, H. K. (1967). Biochimica et Biophysica Acta 137, 484-497.

Dunnett, C. W. (1955). American Statistical Association Journal 50, 1096-1121.

Galbraith, H. \& Miller, T. B. (1973). Journal of Applied Bacteriology 36, 659-675.

Henderson, C. (1973). Journal of Agricultural Science, Cambridge 81, 107-112.

Hodge, J. E. \& Hofreiter, B. T. (1962). In Methods in Carbohydrate Chemistry, vol. 1, pp. 380-394. [R. L. Whistler and M. L. Wolfrom. editors]. New York: Academic Press.

Jacobson, D. R., Lindahl, I. L., McNeill, J. J., Shaw, J. C., Doetsch, R. N. \& Davis, R. E. (1957). Journal of Animal Science 16, 515-524.

Jenkins, T. C. \& Palmquist, D. L. (1984). Journal of Dairy Science 67, 978-986.

Laby, R. H. (1975). In Digestion and Metabolism in the Ruminant, pp. 537-550. [I. W. McDonald and A. C. I. Warner, editors]. Armidale NSW 2351. Australia: The University of New England Publishing Unit.

McAllan, A. B., Knight, R. \& Sutton, J. D. (1983). British Journal of Nutrition 49, 433-440.

Maczulak, A. E., Dehority, B. A. \& Palmquist, D. L. (1981). Applied and Environmental Microbiology 42, $856-862$

Prins, R. A., Van Nevel, C. J. \& Demeyer, D. I. (1972). Antonie van Leeuwenhoek Journal of Microbiology and Serology 38, 281-287.

Reese, E. T. \& Maguire, A. (1969). Applied Microbiology 17, 242-245.

Stanier, G. \& Davies, A. (1981). British Journal of Nutrition 45, 567-578.

Suto, T. (1973). In Methods in the Clinical Examination of the Bovine, pp. 39-42 [R. Nakamura, T. Yonemura and T. Suto, editors]. Tokyo: Nosan Gyoson Bunka Kyokai. (In Japanese).

Sutton, J. D., Knight, R., McAllan, A. B. \& Smith, R. H. (1983). British Journal of Nutrition 49, 419-432.

Takahashi, J., Abekawa, Y. \& Yamada, K. (1960). Nippon Nogei Kagaku Kaishi 34, 1043-1045.

Ushida, K., Miyazaki, A. \& Kawashima, R. (1982). Japanese Journal of Zootechnical Science 53, 412-416.

Wakita, M., Yamada, Y. \& Hoshino, S. (1985). Proceedings of the 3rd AAAP Animal Science Congress 2 , 866-868. 